\title{
Seismic Stability Analysis of Homogeneous and Layered Soil Slopes by LEM
}

\author{
Md. Mahmud Sazzad \\ Associate professor, \\ Department of Civil \\ Engineering, Rajshahi \\ University of Engineering \& \\ Technology, Bangladesh
}

\author{
Swapon Mazumder \\ Civil Engineer, Graduated from \\ Rajshahi University of \\ Engineering \& Technology, \\ Bangladesh
}

\author{
Md. Moniruzzaman Moni \\ Civil Engineer, Graduated from \\ Rajshahi University of \\ Engineering \& Technology, \\ Bangladesh
}

\begin{abstract}
The stability of slopes is a major concern in the field of geotechnical engineering. Usually two-dimensional analyses based on limit equilibrium methods are implemented in this field due to their simplicity and effectiveness. In this paper, the stability of model soil slopes for homogeneous and layered soil with and without earthquake has been analyzed and the related results have been reported. It is noted that the factor of safety decreases with the increase of horizontal seismic coefficent for both the slopes of homogeneous and layered soil. Horizontal seismic coefficent alone affects the stability of slope severely than the combined effect of horizontal and vertical seismic coefficients. The effect of slope angle and cohesion of soil on the stability of slopes have also been reported in this study. The factor of safety of slope increases with the increase of the ratios of cohesion of two soil layers $c_{2} / c_{1}$ ( $c_{2}$ is variable while $c_{1}$ is constant) up to a certain value and beyond that, the factor of safety remains constant.
\end{abstract}

\section{General Terms}

Slope stability analysis considering earthquake effect.

\section{Keywords}

Slope Stability, Seismic coefficients, Factor of Safety, Cohesion, LEM.

\section{INTRODUCTION}

Slope stability analysis is an enormously important deliberation in the design and construction of earth dams, embankments, bridge abutments, retaining walls and various other civil engineering structures. In construction areas, the slope may fail due to rainfall, increase in ground water table and change in stress condition. Likewise, the natural slopes that have been stable for many years may suddenly fail due to change in geometry, external forces and loss of shear strength (Abramson et al. 2002). Tayler and Burns (2005) reported that the earthquake is the greatest threat to the long term stability of slopes, particularly in earthquake active zones. Earthquake induced ground shaking causes failure to slopes that were marginally stable before earthquake. In such circumstances, the proper assessment of the stability of slope becomes the primary concern.

The stability analysis of slope considering the effect of earthquake can be analyzed by different methods such as the pseudo-static method, Newmark's sliding block method and numerical techniques. In the present study, the pseudo-static method is used in which the earthquake loading is represented by a horizontal static force. This horizontal static force is computed by multiplying the weight of structure by the seismic coefficients. The advantage of this method lies in its simplicity. There were several studies in the literature that considered the effect of earthquake in the stability of slopes.
For example, Melo and Sharma (2004) carried out a parametric study on the choice of the seismic coefficients in a more rational way to investigate the effect of earthquake for pseudostatic analysis. Similar study was carried out by Kandolkar et al. (2010). Miraboutalebi et al. (2011) studied the effect of bedrock inclination on the seismic slope stability. Chatterjee and Choudhury (2012) reported the seismic stability analysis of soil slopes using the analytical and numerical approaches. Recently, Gao and Lie (2013) studied the effect of seismic action direction on the stability of slope and reported that the stability of slope is lower than the stability of natural condition when the direction of horizontal earthquake inertia force outside toward slope. Even though several research works have already been conducted for the stability analysis of slope by limit equilibrium method (LEM). and finite element method (FEM) considering the effect of earthquake for homogeneous soil; however, a very limited study for layered soil on the stability analysis of slope considering the earthquake has been reported so far. Consequently, this paper presents a comprehensive study of the stability of model soil slopes of homogeneous and layered soil subjected to earthquake. The main objectives of this study are: (i) to study the effect of seismic coefficients on the stability of slopes of both homogeneous and layered soil; (ii) to examine the effect of cohesion and slope angle on the stability of slope for varying seismic coefficients. For this purpose, the slopes of homogeneous and layered soil are analyzed and the associated results are presented.

\section{ANALYSIS TECHNIQUE}

\subsection{Load-based Seismic Slope Stability}

\section{Analysis}

Load-based procedure is one of the earliest procedures for seismic slope stability analysis. In this approach, the earthquake loading is represented by a horizontal static force, which is equal to the weight of soil multiplied by the seismic coefficient. The coefficient can be estimated empirically. The pseudo-static force is then incorporated in a conventional limit equilibrium analysis and the factor of safety is computed (Tan, 2006).

\subsection{Limit Equilibrium Principle}

Mohr-Coulomb model is the most widely used material model which is utilized to determine the shear strength $\left(\tau_{f}\right)$ along the sliding surface (Aryal, 2006). According to Janbu (1973), a state of limit equilibrium exists when the mobilized shear stress $(\tau)$ is expressed as a fraction of the shear strength. The shear strength is usually expressed by the Mohr-Coulomb linear relationship, where the $\tau_{f}$ and $\tau$ are defined by-

Shear strength (available): 


$$
\tau_{f}=c^{\prime}+\sigma^{\prime} \tan \phi^{\prime}
$$

Shear stress (mobilized):

$$
\tau=\frac{\tau_{f}}{F}=\frac{c^{\prime}+\sigma^{\prime} \tan \phi^{\prime}}{F}
$$

where, $c^{\prime}$ and $\phi^{\prime}$ are the effective cohesion and friction angle, respectively, and $F$ is the factor of safety (FOS).

The shear strength that is available depends on the type of soil and the effective normal stress, whereas the shear stress that is mobilized depends on the external forces acting on the soil mass. The FOS can be defined in three ways: Limit equilibrium, force equilibrium and moment equilibrium (Abramson et al. 2002). The first definition is based on the shear strength whereas the second and third definitions are based on force equilibrium and moment equilibrium conditions for resisting and driving force and moment components, respectively (Aryal, 2006).

\subsection{Limit Equilibrium Methods}

Conventionally, the slope stability analysis is carried out by LEM. This method is statically indeterminate. Presumption is needed to determine the factor of safety using the LEM. Among the LEMs, the Bishop method (1955) is the widely used. The application of LEM is limited to the slope of simple geometry. The solution of LEM can become inadequate in case the slope fails by complex mechanism such internal deformation, brittle failure, etc.

\subsection{Geometric Model of Slope}

A number of problems for different slope angles are solved in this paper. Fig. 1 shows the geometric model of a slope of homogeneous soil while Fig. 2 presents the geometric model of a slope of layered soil. In Figs. 1 and 2, $\beta$ indicates the angle of slope with the horizontal.

\subsection{Material Properties}

The properties of soil used in the present study are presented in Table 1. Two types of soils are considered. Either soil-1 or soil-2 is used for the analysis of a slope of homogeneous soil whereas both soil-1 and soi-2 are used for the stability analysis of slopes of layered soil.

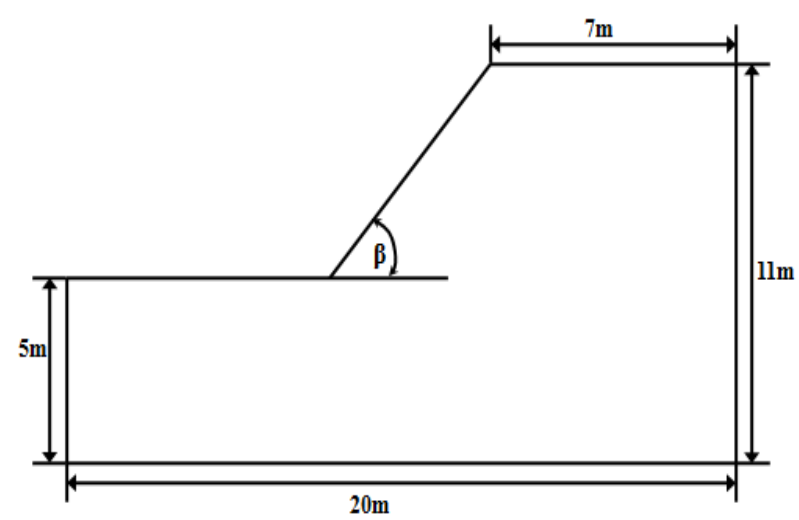

Fig 1: Geometric model of a slope of homogeneous soil

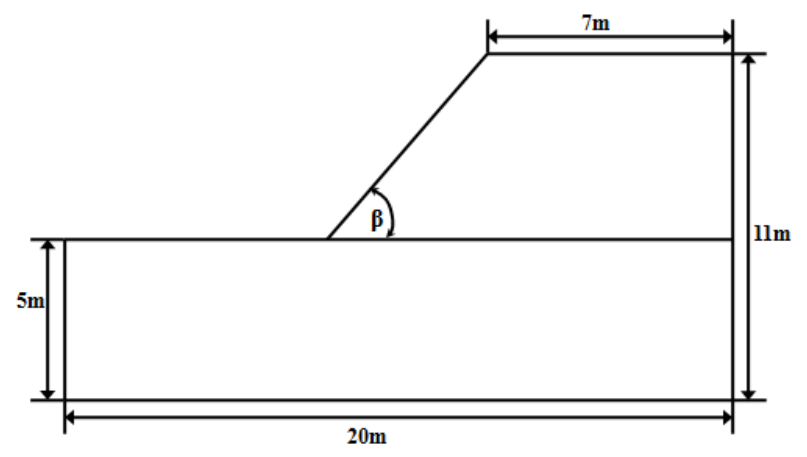

Fig 2: Geometric model of a slope of layered soil

Table 1 Properties of soil considered in the present study

\begin{tabular}{|c|c|c|c|}
\hline Material & $\begin{array}{c}\text { Unit } \\
\text { weight } \\
\left(\mathbf{k N} / \mathbf{m}^{\mathbf{3}}\right)\end{array}$ & $\begin{array}{c}\text { Friction } \\
\text { angle } \\
(\mathbf{d e g r e e})\end{array}$ & $\begin{array}{c}\text { Cohesion } \\
\left(\mathbf{k N} / \mathbf{m}^{\mathbf{2}}\right)\end{array}$ \\
\hline Soil-1 & 18.5 & 10 & 25 \\
\hline Soil-2 & 17 & 5 & 15 \\
\hline
\end{tabular}

\section{NUMERICAL ANALYSIS BY LEM}

In the present study, a number of numerical analyses have been performed by the software GEO5 (2014). Bishop method (1955) is used for limit equilibrium analysis. For LEM, the geometric model is incorporated in the GEO5 software. After incorporating the model, the properties of soil are assigned for the specified interface. In the analysis stage, a slip surface is added. In this paper, circular slip surface is used. After assigning the properties of soil and adding a suitable slip circle, the analysis method is chosen. In this paper, optimization type is taken as analysis type. Finally, seismic coefficients are added to the slope and the stability analysis of slope is carried out.

\section{RESULTS AND DISCUSSION 4.1 Slope of Homogeneous Soil}

An idealized slope of $11 \mathrm{~m}$ height with $\beta$ of $30,45,60$ and 75 degrees has been selected for the present work. The analyses have been carried out by using two types of soil (soil-1 or soil-2, whichever applicable).

\subsubsection{Effect of Earthquake}

The stability of slope of homogeneous soil-1and slope of homogeneous soil-2 with $\beta=45^{\circ}$ is first analyzed using GEO5 (2014) considering the effect of earthquake. Note that the effect of earthquake is incorporated here using the suitable seismic coefficients. Fig. 3 depicts the variation of the factor of safety with $K_{h}$ for a constant $K_{v} / K_{h}=0.5$, where $K_{v}$ and $K_{h}$ are the vertical and horizontal seismic coefficients, respectively. The factor of safety without considering any earthquake (i.e. without any $K_{v}$ or $K_{h}$ ) shows a higher value of factor of safety compared to that with considering the earthquake for a particular soil, as expected. From Fig. 3, it is also observed that the factor of safety decreases with the increase of $K_{h}$. Note also that the trend of decreasing factor of safety is almost same for both the slope of homogeneous soil-1 and slope of homogeneous soil-2. 
Fig. 4 depicts the variation of factor of safety with different $K_{v} / K_{h}$ for slope of homogeneous soil-1 $\left(\beta=45^{\circ}\right.$ ) while Fig. 5 shows the variation of factor of safety with different $K_{v} / K_{h}$ for slope of homogeneous soil-2 $\left(\beta=45^{\circ}\right)$. From Figs. 4 and 5 it is clear that the factor of safety is minimum when $K_{v} / K_{h}=0$ i.e, when only $K_{h}$ affects on slope. It reveals that the role of $K_{h}$ is dominant in the analysis of slope while considering the effet of earthquake. Effect of $K_{h}$ is more hazardous than the combined effect of $K_{v}$ and $K_{h}$.

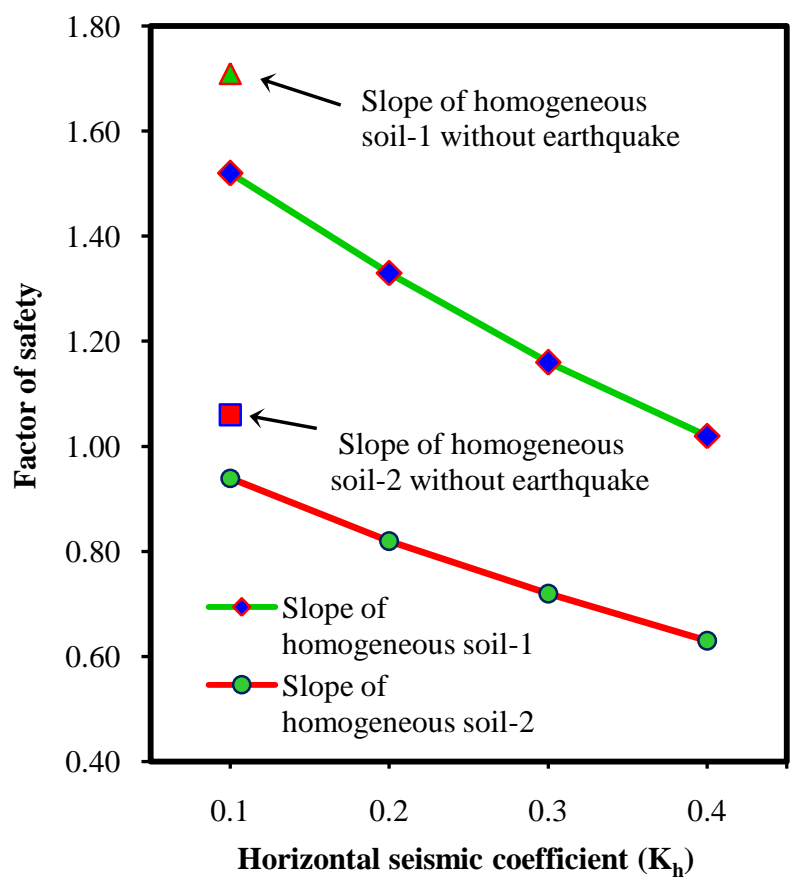

Fig. 3: Variation of the factor of safety with $K_{h}$ for $K_{v} / K_{h}=0.5$ with $\boldsymbol{\beta}=\mathbf{4 5}^{\circ}$

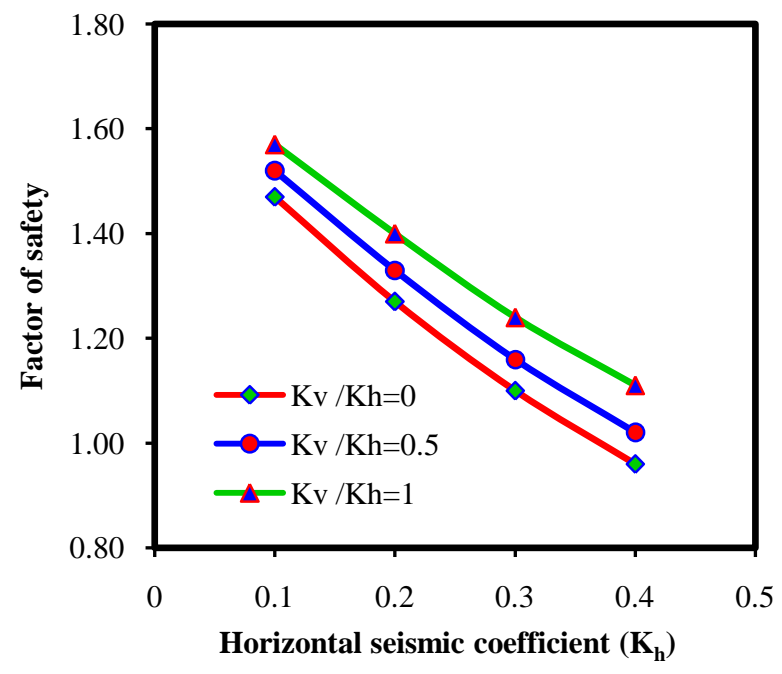

Fig. 4: Variation of factor of safety with different $K_{v} / K_{h}$ for slope of homogeneous soil-1 $\left(\beta=45^{\circ}\right)$

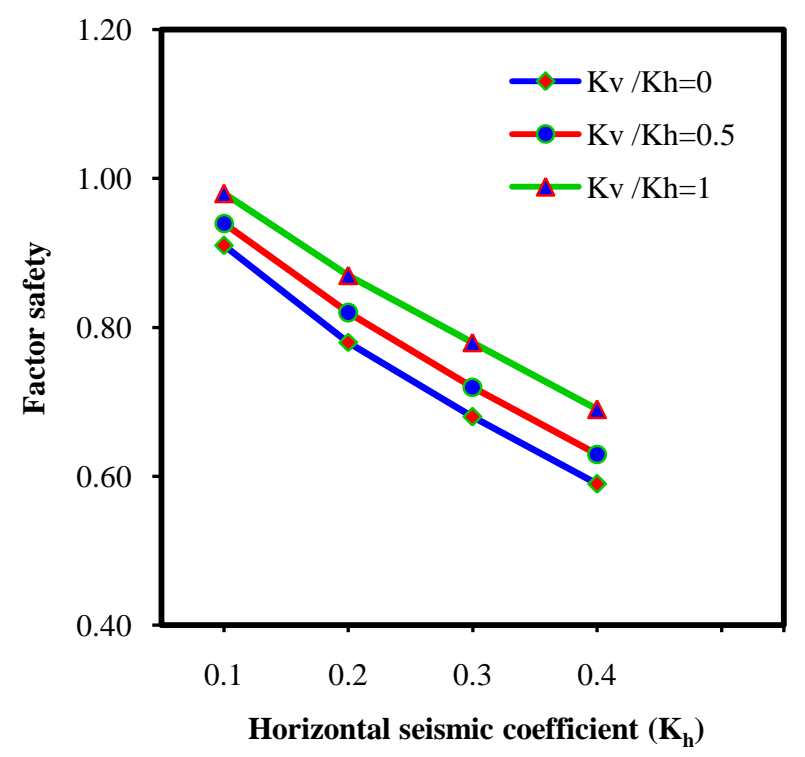

Fig. 5: Variation of factor of safety with different $K_{v} / K_{h}$ for slope of homogeneous soil-2 $\left(\beta=45^{\circ}\right)$

\subsubsection{Effect of Slope Angle}

Four different slope angles $\left(30^{\circ}, 45^{\circ}, 60^{\circ}\right.$ and $\left.75^{\circ}\right)$ are considered in this study. A number of analyses have been performed considering earthquake and no earthquake conditions for both the slope of homogeneous soil-1 and homogeneous soil-2. Fig. 6 shows the effect of slope angle on the factor of safety of slope of homogeneous soil-1 while Fig. 7 shows the effect of slope angle on the factor of safety of slope of homogeneous soil-2. From Figs. 6 and 7, it is observed that the factor of safety decreases as the slope angle increases considering earthquake and no earthquake conditions.

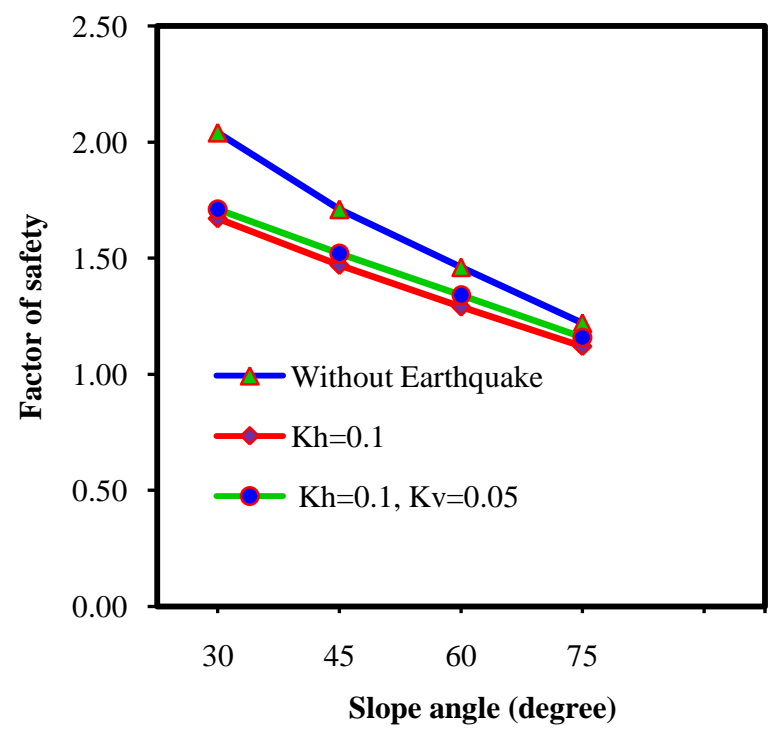

Fig. 6: Effect of slope angle on the factor of safety of slope of homogeneous soil-1 


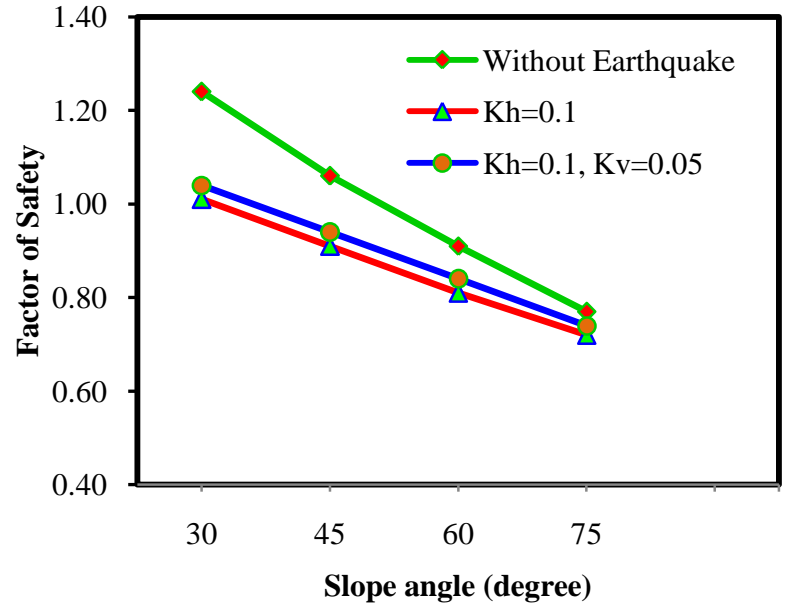

Fig. 7: Effect of slope angle on the factor of safety of slope of homogeneous soil-2

\subsection{Slope of Layered Soil}

The stability of slope of layered soil has been analyzed considering two cases. In analysis case-1, soil-2 is used in upper portion of the slope and soil-1 is used in the foundation layer. In analysis case-2, soil-1 is used in the upper portion of the slope and soil-2 is used in the foundation layer. This is done with a view to assess the effect of the position of the relatively weak soil layer on the stability of slopes considering earthquake.

\subsubsection{Effect of Earthquake}

Fig. 8 depicts the variation of the factor of safety of slope of layered soil for different $K_{v} / K_{h}$ ratios with $\beta=45^{\circ}$ considering the analysis case- 1 while Fig. 9 presents the variation of the factor of safety of slopes of layered soil for different $K_{v} / K_{h}$ ratios with $\beta=45^{\circ}$ considering the analysis case-2. From Figs. 8 and 9 , it is observed that the factor of safety is minimum when $K_{v} / K_{h}=0$, i.e. when only $K_{h}$ affects the slope. The result is similar to that of homogeneous soil. Effect of $K_{h}$ is more severe than the combined effect of $K_{v}$ and $K_{h}$. Note that the popsition of the relative weak soil layer either above the foundation soil or as a foundation soil has no significant influnce in computing the factor of safety.

However, it has noticeable effect on the formation of the slip circle during earthquake. Fig. 10 shows the slip surface of the slope of layered soil $\left(\beta=45^{\circ}\right)$ for case-1 with earthquake ( $K_{h}$ $=0.1$ and $\left.K_{v}=0.05\right)$ while Fig. 11 shows the slip surface of the slope of layered soil $\left(\beta=45^{\circ}\right)$ for case- 2 with earthquake ( $K_{h}=0.1$ and $K_{v}=0.05$ ) using LEM. When soil-2 (a relatively weak soil) is placed in the upper portion of the slope of layered soil, the slip surface runs within the upper layer only. However, when soil-2 is placed in the foundation layer, the slip surface extends beyond the upper layer of the soil to the foundation layer.

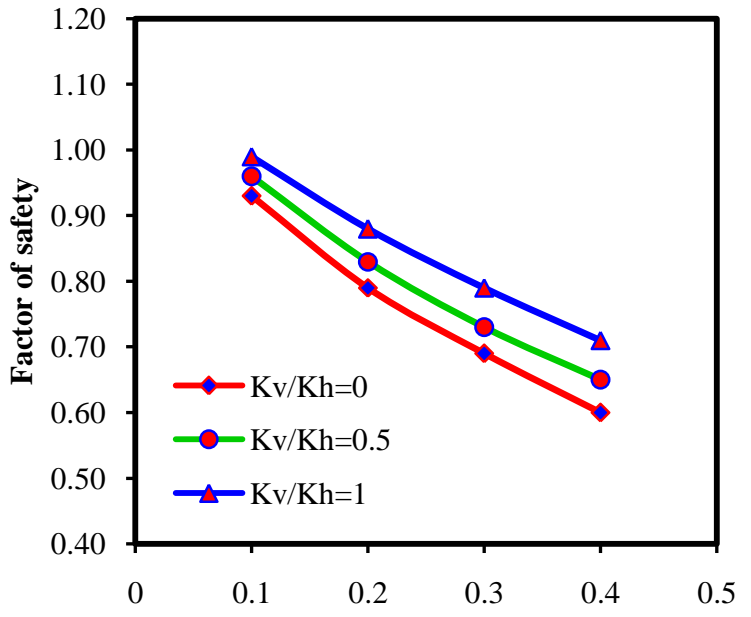

Horizontal seismic coefficient $\left(K_{h}\right)$

Fig. 8: Variation of factor of safety for various $K_{v} / K_{h}$ ratio for a slope of layered soil $\left(\beta=45^{\circ}\right)$ for case- 1

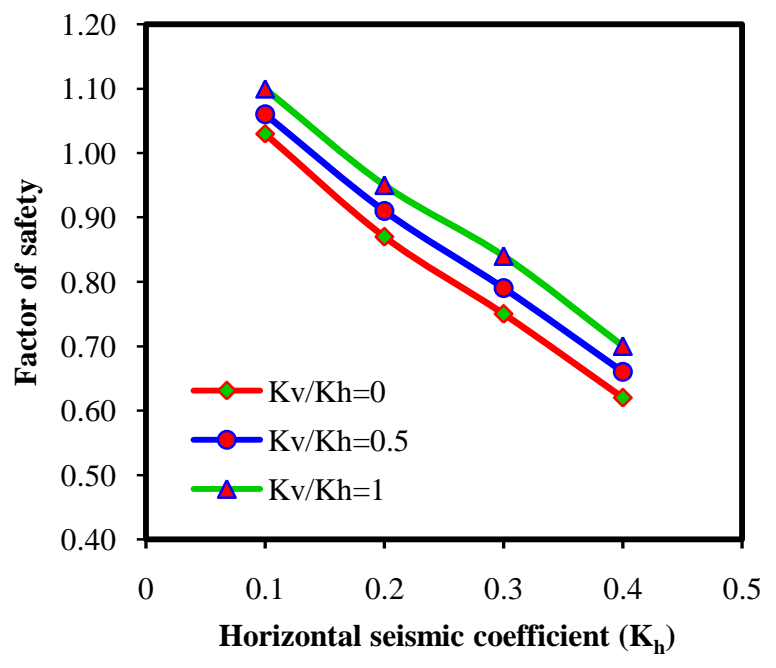

Fig. 9: Variation of factor of safety for various $K_{v} / K_{h}$ ratio for a slope of layered soil $\left(\beta=45^{\circ}\right)$ for case-2

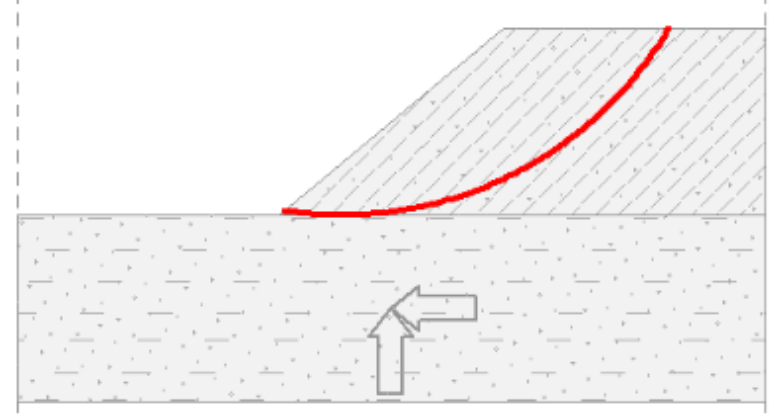

Fig. 10: Slip surface in layered soil ( $\beta=45^{\circ}$ ) for case-1 with earthquake ( $K_{h}=0.1$ and $\left.K_{v}=0.05\right)$ using LEM 


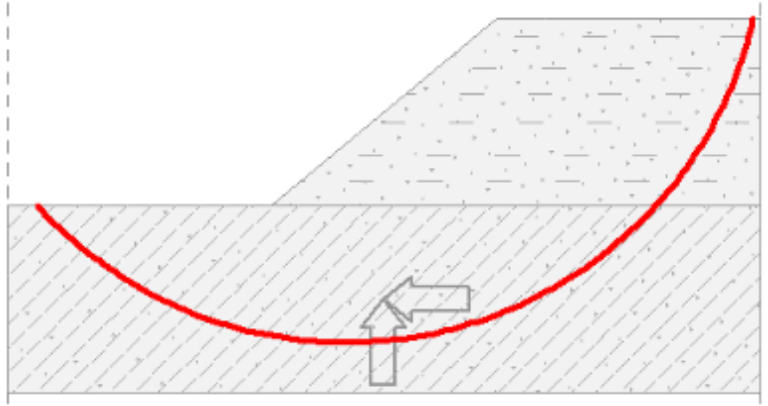

Fig. 11: Slip surface in layered soil $\left(\beta=45^{\circ}\right)$ for case-2 with earthquake ( $K_{h}=0.1$ and $\left.K_{v}=0.05\right)$ using LEM

\subsubsection{Effect of Cohesion}

Several analyses are carried out using soil-1 for $\phi=0$ condition to account for the effect of cohesion on the factor of safety during earthquake only. The analyses are carried out using a constant value of cohesion for upper layer of soil $\left(c_{1}\right)$ and nine different values of cohesion $\left(c_{2}\right)$ for foundation layer.

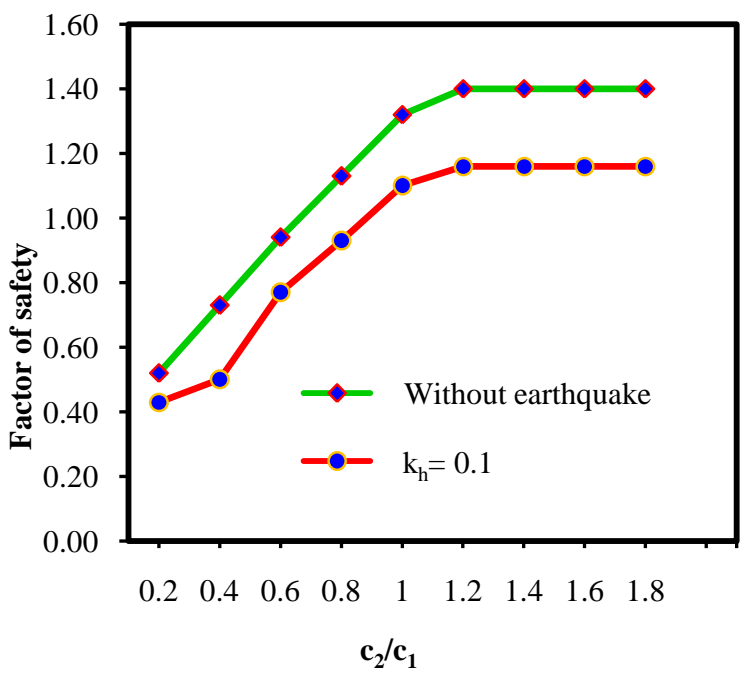

Fig 12: Effect of $c_{2} / c_{1}$ on a slope of layered soil $\left(\boldsymbol{\beta}=45^{\circ}\right)$

Fig. 12 depicts the effect of the variation of $c_{2} / c_{1}$ on the factor of safety of slope of layered soil $\left(\beta=45^{\circ}\right)$ with and without earthquake. It is worth noting that the factor of safety increases gradually with $c_{2} / c_{1}$ up to a value of 1.2 and beyond that value, the factor of safety remains constant for a slope of $45^{\circ}$. Similar result is observed in Fig. 13 for $\beta=60^{\circ}$. Factor of safety varies up to a value of $c_{2} / c_{1}=1$ and beyond that, factor of safety remains constant for a slope of $60^{\circ}$.

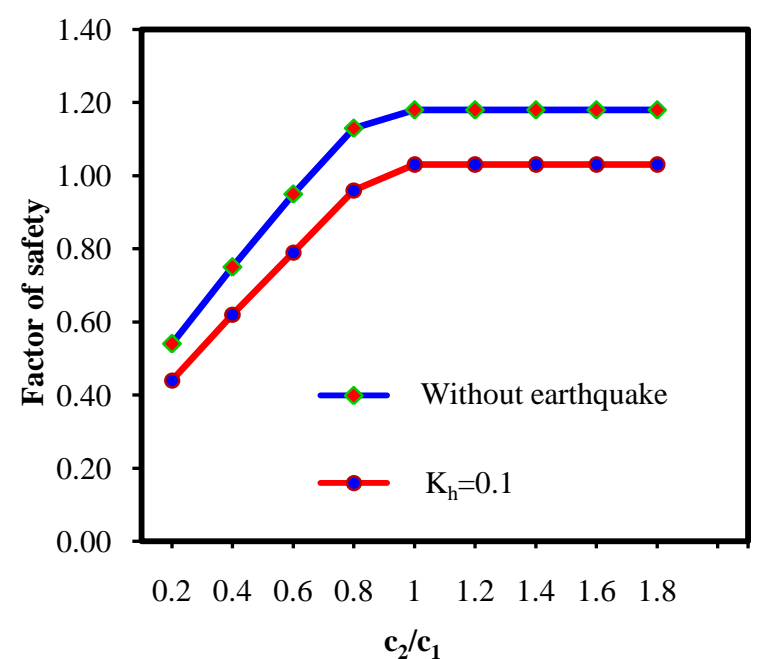

Fig. 13: Effect of cohesion $\left(c_{2} / c_{1}\right)$ variation for a slope of layered soil $\left(\boldsymbol{\beta}=60^{\circ}\right)$

\section{CONCLUSIONS}

In the present study, numerical analysis is carried out to investigate the effect of earthquake on the stability of slopes of homogeneous and layered soil. The major findings of the study are as follows:

(1) The factor of safety decreases with the increase of the horizontal seismic coefficient $\left(K_{h}\right)$ for both the slope of homogeneous and layered soil.

(2) Effect of the horizontal seismic coefficient $K_{h}$ is more severe than the combined effect of vertical seismic coefficient $\left(K_{v}\right)$ and horizontal seismic coefficient $\left(K_{h}\right)$.

(3) If a relatively weak soil layer is located below the good soil layer, the slip surface extends beyond the top soil layer to the weak soil layer.

(4) The factor of safety of slopes of layered soil increaes with the increase of the ratios of cohesion of two soil layers $c_{2} / c_{1}$ up to a certain value and beyond that, the factor of safety remains constant.

\section{REFERENCE}

[1] Abramson, L. W., Lee, T. S., Sharma, and Boyce G. M. 2002. Slope Stability Concepts, Slope Stabilization and Stabilization Methods, Second edition, published by John Willey \& Sons, Inc., pp. 329-461.

[2] Aryal, K. P. 2006. Slope stability evaluations by limit equilibrium and finite element methods. Doctoral thesis at Norwegian University of Science and Technology.

[3] Bishop A. W. 1955. The use of slip circles in stability analysis of slopes, Geotechnique, Vol. 5 No. 1, pp. 7-17.

[4] Chatterjee, K. and Choudhury, D. 2012. Seismic stability analysis of soil slopes using analytical and numerical approaches. ISET Golden Jubilee Symposium. Paper No. C005. 
[5] Gao, F. and Lie, W. 2013. Study on effect of seismic action direction on slope stability. International Efforts in Lifetime Earthquake Engineering, pp. 656-662.

[6] GEO5 v18. 2014. Users manual, Fine software company, Czech Republic.

[7] Janbu, N. 1973. Slope Stability Computations. Embankment Dam Engineering, Casagrande Volume, pp. 47-86.

[8] Kandolkar, S. S., Aldonkar, S. S. and Savoikar, P. P. 2010. Rational Pseudo-static stability analysis of embankments, Indian Geotechnical Conference, India, pp. 135-138.

[9] Miraboutalebi, M., Askari, F. and Farzaneh, O. 2011. Effect of bedrock inclination on seismic slope stability according to Iran seismically data,
International Journal of Civil Engineering, Vol. 9, No. 4, pp. 247-254.

[10] Melo, C. and Sharma, S. (2004). Seismic coefficients for pseudostatic slope analysis, $13^{\text {th }}$ World Conference on Earthquake Engineering, Canada, Paper ID No. 369.

[11] Tan, D. 2006. Seismic slope safety - Determination of critical slip surface using acceptability criteria. Doctoral thesis at Imperial College University of London.

[12] Taylor, M. J. and Burns, S. F. 2005. Slope and seismic stability of Castle Lake Debris Dam, St. Helens, Washington, Landslide and Avalanches: ICFL, Norway, Edr. Senneset, Flaateand Larsen. 